\section{Direct speech and language therapy for children with cerebral palsy: findings from a systematic review}

\author{
Lindsay Pennington* PhD, Research Fellow, Speech and \\ Language Sciences, University of Newcastle upon Tyne, \\ Newcastle upon Tyne; \\ Juliet Goldbart PhD, Reader; \\ Julie Marshall MPhil, Senior Lecturer and Speech and \\ Language Therapy Clinic Manager, Manchester \\ Metropolitan University, Manchester, UK. \\ *Correspondence to first author at Speech and Language \\ Sciences, School of Education, Communication and \\ Language Sciences, University of Newcastle upon Tyne, \\ King George VI Building, Queen Victoria Road, \\ Newcastle upon Tyne NE1 7RU, UK. \\ E-mail: lindsay.pennington@ncl.ac.uk
}

Children with cerebral palsy (CP) often have speech, language, and/or communication disorders ${ }^{1}$ and are referred to speech and language therapy (SLT). They may also be referred to SLT services for dysphagia: treatment of which is beyond the scope of this review. Although the exact prevalence of the communication disorders associated with CP is not known, it has been estimated that approximately $20 \%$ of children with a diagnosis of $\mathrm{CP}$ have severe communication impairment and are classified as non-verbal. ${ }^{2}$ Many more will have less severe speech and communication disorders as a consequence of their motor impairment, or disorders arising from speech, language, and cognitive processing deficits associated with CP.

Speech and language therapy aims to maximize children's ability to communicate through speech, gesture, and/or supplementary means, such as communication aids, and to enable them to become independent communicators. As the problems experienced by children with a diagnosis of CP range widely, there is no single universally appropriate form of treatment. Intervention can focus on speech, ${ }^{3-4}$ on expressive or receptive language development, ${ }^{5}$ or on helping children to develop conversation skills, such as asking questions and 'repairing' conversation when misunderstandings occur. ${ }^{6-8}$ It can be given to children directly on a one-to-one basis or in groups, or indirectly by training familiar conversation partners to alter communication environments and provide more opportunities for interaction. SLT also varies in its intensity and the location in which it is given.

As part of a larger study, we undertook a broad, exploratory systematic review to investigate the forms of SLT currently given directly to children with different types and severities of communication disorders associated with CP. This review was also intended to investigate SLTs and their relative effectiveness in order to inform future research. The broader review is published and will be updated in The Cochrane Library. ${ }^{9}$

\section{Methods}

\section{STUDIES}

For inclusion in the review, studies had to meet the following criteria. (1) The design had to contain an element of control. This could include single-case experimental designs or group studies with controls. (2) Participants had to be aged up to 19 years inclusive with a diagnosis of $\mathrm{CP}$ of any type or severity. No exclusions were to be made on the grounds of additional impairments, such as intellectual or sensory impairments, or the presence of epilepsy. This age range was selected because people in England who have identified special needs are entitled to statutory education provision, which could specify SLT, up to 19 years of age. (3) Interventions had to target children's speech, language, and/or communication development, and had to be given directly by a speech and language therapist or a supervised SLT assistant. Interventions could be provided in any setting. Those given as part of a holistic approach, such as conductive education, were excluded. No exclusions were made on the country in which the research was undertaken or the language used.

Outcome measures sought were the following: (1) measures of communication - (a) children's expressive and receptive language skills, speech production, conversation/pragmatic 
skills, intelligibility, communicative competence, (b) communication partners' conversation and interaction strategies; (2) family stress and coping; (3) satisfaction of patient and family with treatment; (4) non-compliance with treatment.

\section{SEARCH STRATEGY}

The following search strategy was used to locate published reports: (a) cerebral pals* AND child; (b) speech OR speech disorder OR speech intelligibility OR speech therap* OR speech and language therap* OR speech pathol* OR speech and language pathol*; (c) language OR language disorders OR language development disorders OR sign language OR child language OR language therap*; (d) communication OR communication aids for disabled OR communication disorders OR manual communication OR nonverbal communication OR augmentative and alternative communicat*; (e) \#b OR \#c OR \#d; (f) a AND e.
The following electronic databases were searched from 1980 or their inception (whichever was later) until the end of December 2002: Medline; CINAHL; EMBASE; Psych Info; Web of Science; Linguistic and Language Behaviour Abstracts; British Education Index; National Research Register (completed and ongoing research); ERIC; Aslib Index to UK theses; SIGLE.

The following journals were hand-searched from 1980 onwards or from their inception (whichever was later): 'International Journal of Language and Communication Disorders', 'AAC: Augmentative and Alternative Communication', 'Child Language Teaching and Therapy', 'Developmental Medicine \& Child Neurology', 'Journal of Child Psychology and Psychiatry and Allied Disciplines', 'European Journal of Special Needs Education', 'Journal of Communication Disorders', 'Journal of Psycholinguistic Research', 'Journal of Special Education', 'International Journal of Rehabilitation Research', 'Folia Phoniatrica et Logopaedica',

Table I: Characteristics of included studies*

\begin{tabular}{lrr}
\hline Study and design & Participants \\
\hline Campbell and Stremel-Campbell 1982 & USA. One male aged 10 years with & Interventions \\
& CP affecting lower limbs, and & Correct production of 'is/are' in three syntactic \\
moderate language delay & structures ('wh' questions, 'yes/no' reversal questions, \\
Single-case experimental design: & and statements) was reinforced using behaviour \\
within subject multiple baseline & modification techniques. Trained to criterion ( $80 \%$ \\
$\begin{array}{l}\text { across two behaviours, plus one } \\
\text { control untreated behaviour }\end{array}$ & correct in two consecutive five-session blocks) \\
& Two 15 minute sessions were given each school day,
\end{tabular}

\section{Davis et al. 1998}

Single-case experimental design: multiple baseline design across three communication partners. One partner did not intervene and acted as control

\section{Hunt et al. 1986}

Single-case experimental design. Multiple baseline across four request situations
USA. Male aged 15 years, with spastic quadriplegia with athetosis, who communicated using vocalization, gesture and one word phrases via voice output communication aid containing $500+$ stored messages. Other development not reported. Communication partners: two female graduate students employed as home tutors of maths, reading, and communication, and a male personal care attendant. No further details on the communication partners given

USA. Female aged 7 years with severe intellectual impairment and multiple disabilities. No further details provided on underlying impairments.

Communicated by vocalization, one gesture, two manual signs, and by touching the listener. Could not use pictures for communication. Limited success matching representation to real object

\section{Hurlbut et al. 1982}

Single-case experimental design. Alternating treatments design across three participants. Compared trials with acquisition and response generalization for Blissymbols and iconic symbols
USA. Three males, aged 14, 16, and 18 years with severe spastic quadriplegia, moderate athetosis and severe

chorioathetosis, and severe speech impairment. No other further information supplied on cognitive and sensory skills. Communicated by idiosyncratic gestures, yes/no responses, and 1 to 3 Blissymbols

Communication partners trained to follow correct response to two obligatory requests for information with a non-obligatory request. Treatment two to three times per week at home. Thirty-six sessions in total

Interrupted chain training of four requests. Trained to criterion (three consecutive correct productions of current target). Treatment given twice daily in familiar routines, with $\mathbf{5 5}$ sessions in total

Participants trained to use five Blissymbols and five iconic symbols to criterion (10 correct responses) in response to 'What's this?'. Teaching strategies included modelling, verbal prompting, physical and verbal prompting, and reinforcement. Duration and frequency of therapy sessions not specified

*Copyright $\odot$ Cochrane Library reproduced with permission. 
'Applied Psycholinguistic Research', 'Journal of Speech, Language and Hearing Research', 'Australian Journal of Communication Disorders', 'American Journal of Speech Language Pathology', 'International Journal of Disability, Development and Education', 'Speech, Language and Hearing in Schools'. (Current titles are given for journals experiencing name changes since 1980.)

Published conference proceedings of the following organizations were checked: European Academy of Child Development (1996-2002), International Society for Alternative and Augmentative Communication (1996-2002), American Speech and Hearing Association (1999-2002), Royal College of Speech and Language Therapists (1998-2002). Reference lists of all studies selected for possible inclusion were checked for other eligible studies. Authors of included trials were contacted for unpublished studies. Calls for assistance were made through national professional associations.
METHOD OF REVIEW

One author searched for relevant reports and assessed them for inclusion using the strategies and criteria above. Translations were sought when necessary. Two other authors independently assessed separate random samples comprising $25 \%$ of all identified studies, plus any studies whose inclusion status was ambiguous. Two authors then independently assessed the methodological quality of each study identified for inclusion, using a previously validated checklist ${ }^{10}$ and a checklist for single-case experiments developed from methodology texts. ${ }^{11-13}$ Attention was paid to whether studies demonstrated protection from the following types of bias: selection bias, i.e. whether the study had true random sequencing, true concealment up to the time of allocation, comparison of known confounding variables between groups, comparison of developmentally similar processes in single-case experimental designs; performance bias, i.e. whether the study had

Table I: continued

\begin{tabular}{|c|c|c|}
\hline Outcome measures & Outcomes & Notes \\
\hline $\begin{array}{l}\text { Frequency of correct 'is/are' production in } \\
\text { the three target syntactic structures was } \\
\text { recorded online by an unblinded observer in } \\
\text { each training session, and by a second assessor } \\
\text { in } 17 \% \text { of sessions. Mean agreement on child's } \\
\text { and teacher's responses, mean } 96 \% \text {, } \\
\text { (range } 80-100 \% \text { ) across all categories }\end{array}$ & $\begin{array}{r}\text { Stable baseline, low levels of production. } \\
\text { Steady increase in treatment sessions. } \\
\text { Generalization to untreated } \\
\text { communication situation }\end{array}$ & $\begin{array}{r}\text { Second single case using same design also } \\
\text { reported in same paper. Second child did } \\
\text { not have CP and information not reported } \\
\text { in this review }\end{array}$ \\
\hline $\begin{array}{l}\text { Percentage responses to blocks of five } \\
\text { elicitation sequences, recorded by unblinded } \\
\text { assessor. Reliability of treatment according to } \\
\text { protocol and data coding was checked on } 25 \% \\
\text { of sessions with a second, unblinded assessor. } \\
\text { Mean agreement } 98 \% \text { (range } 94-100 \% \text { ) }\end{array}$ & $\begin{array}{r}\text { Target produced rarely during baseline } \\
\text { with each conversation partner. Target } \\
\text { increased only when partner used } \\
\text { elicitation sequence }\end{array}$ & $\begin{array}{r}\text { Two children took part in the study. The } \\
\text { second child did not have CP and data } \\
\text { from that participant is not included } \\
\text { in this review }\end{array}$ \\
\hline $\begin{array}{r}\text { Requests under investigation were } \\
\text { tested daily. Content, form, and } \\
\text { function of communicative behaviour } \\
\text { was assessed by therapist. Reliability of } \\
\text { assessment was checked by independent } \\
\text { observer in } 20 \% \text { sessions. } 100 \% \text { agreement }\end{array}$ & $\begin{array}{r}\text { Rarely produced targets at baseline. } \\
\text { Steady increase in target behaviour } \\
\text { following initial lag }\end{array}$ & $\begin{array}{l}\text { Three children took part in the study. } \\
\text { Only one had CP. The other children's } \\
\text { results are not included in this review }\end{array}$ \\
\hline $\begin{array}{r}\text { Percentage correct naming of } 10 \text { trained } \\
\text { and } 10 \text { untrained items using Bliss and } \\
\text { iconic language was measured before } \\
\text { and after intervention. Trials to acquisition } \\
\text { for both systems was also calculated. Data } \\
\text { were measured by an unblinded assessor, } \\
\text { and by an independent observer on } \\
\text { approximately half of the sessions. } \\
\text { Mean agreement for each student } 98,98,99 \%\end{array}$ & $\begin{array}{r}\text { Fewer trials to criterion for iconic symbols } \\
\text { than Bliss, generalization, maintenance } \\
\text { and naming of untrained objects greater } \\
\text { with iconic symbols than Bliss for all } \\
\text { three participants }\end{array}$ & \\
\hline
\end{tabular}


differences in types of treatment (co-interventions) between the two groups; exclusion bias, i.e. withdrawal after entry to the trial; detection bias, i.e. 'unmasked' assessment of outcome. Data on the design, participants, measures, and intervention of individual studies were abstracted using checklists developed using a previously published tool. ${ }^{10}$ Where necessary, authors were contacted to provide missing data for the included trials. Data were entered into $\operatorname{RevMan}(4.2)^{14}$ for analysis.

\section{Results}

Searches generated 832 abstracts, of which 737 clearly did not fit the inclusion criteria. Ninety-five full papers were considered, and seven studies fitted the inclusion criteria for this review. Reasons for exclusion included indirect therapy provided, lack of experimental control, and inability to disaggregate results of participants with $\mathrm{CP}$ from those of people with other diagnoses. All studies included in this review comprised single-case experimental designs. Two studies included other participants who did not have CP. Results for children with $\mathrm{CP}$ are reported here. Participants ranged in age from 11 months to 18 years, and had a range of type and severity of CP. Participants also varied widely in the presence and severity of associated disorders. At least seven of the twelve children had cognitive impairment in addition to their motor impairment.

\section{OUTCOMES OF INCLUDED STUDIES}

Intervention aimed to facilitate the development of preintentional communication skills (e.g. maintaining eye contact), functions of conversation (e.g. asking questions, pro- viding information, repeating when misunderstood), and syntactic structure in expressive language (e.g. 'is/are' with verb). Increases in skills were noted in each of the studies, suggesting that the interventions were effective for the individual children involved. As participants and interventions differed, a meta-analysis was not used in the review. A description of individual studies is included in Table I.

Richman and Kozlowski ${ }^{15}$ taught a female with severe intellectual and motor impairment, who was at the preintentional stage of development, to keep her head up, to maintain eye contact, and to produce vocal imitations in interaction, using operant teaching methods, including shaping and contingent reinforcement. Increases in targeted behaviours were observed during treatment phases, with reductions during reversal phases.

Hunt et al. ${ }^{16}$, Pinder and Olswang ${ }^{17}$, and Sigafoos and Couzens $^{18}$ taught children from 11.5 months to 18 years of age, who had varying degrees of intellectual impairment, to produce requests for specific objects or actions using natural methods of communication or symbols. Researchers used operant and micro-teaching techniques, in which elicitors, expectant delay, prompts, and reinforcements were used in graded sequences to facilitate learning. In each of these three studies, intervention effects generalized to untrained requests. Davis et al. ${ }^{19}$ also focused on developing communicative functions, teaching a teenager to produce responses to partners' statements in conversation. Three conversation partners were trained to follow two answered questions with a statement in conversation in order to elicit a non-obligatory response from the child. Responses increased when each conversation partner began to use this elicitation sequence.

Table I: continued

\begin{tabular}{|c|c|c|}
\hline Study and design & Participants & Interventions \\
\hline Pinder and Olswang 1995 & $\begin{array}{r}\text { USA. Four children, ( } 2 \text { males, } 2 \text { females }) \\
\text { aged } 11.5-13.5 \text { months with mixed }\end{array}$ & $\begin{array}{l}\text { Children were taught to request objects or request } \\
\text { more by gaze and/or reaching and grasping. Teaching }\end{array}$ \\
\hline Four single-case experiments & $\begin{array}{r}\text { athetoid or spastic diplegia type CP, } \\
\text { who had difficulty grasping and releasing } \\
\text { objects and did not sit independently. All with } \\
\text { IQ }<50 \text { Bayley Mental Development Index, }\end{array}$ & $\begin{array}{r}\text { strategies included modelling, expectant delay, and } \\
\text { reinforcement. Trained to criterion (request } \geq 50 \% \\
\text { in five consecutive sessions). Twice weekly } \\
\text { sessions of } 50-60 \text { minutes for up to } 12 \text { weeks }\end{array}$ \\
\hline
\end{tabular}

vision correctable with glasses and hearing within normal limits

\section{Richman and Kozlowski 1977}

Single-case experimental design. Multiple baseline with reversal and reinstatement of treatment across three behaviours

\section{Sigafoos and Couzens 1995}

Single-case experimental design
USA. Female aged 9 years, severe spastic quadriplegia and severe cognitive impairment. No further developmental information supplied
Operant teaching strategies were used to encourage the maintenance of eye contact, head control, and the production of vocal imitations. 10 minute therapy sessions given four days per week for 40 weeks

\footnotetext{
Australia. Male aged 6 years with severe CP of unspecified type, who had moderate cognitive impairment, very poor upper limb control, and required assistance for all activities of daily living. Participant was reported to understand various spoken commands and communicated using eye gaze
}

Trained to request objects using eye gaze by creating communicative environment, expectant delay, verbal prompting, increasing expectant delay, and reinforcement of response by use of object requested. 19 sessions over 8 weeks 
However, there was considerable variation in frequency of responses during the intervention phases, and intervention was not implemented with the third partner because the child moved away from the area in which the research was conducted. Hurlbut et al. ${ }^{20}$ trained three teenagers to select and name objects using Blissymbols (whose meanings cannot be guessed from their appearance) and iconic symbols (look like the item/activity they represent). Each child acquired iconic symbols faster than Blissymbols and produced them more frequently in generalization and maintenance checks. Campbell and Stremel-Campbell ${ }^{21}$ trained a child to use 'is/are' correctly in three successive syntactic structures using operant teaching methods, including systematic reinforcement. However, performance varied widely over each phase of the training.

METHODOLOGICAL QUALITY OF INCLUDED STUDIES

All studies included in the review cited children's chronological age, and most gave the type and a rating of the severity of their CP. Three included information on the presence and/or severity of associated disorders, such as intellectual and sensory impairments. However, none included sufficient detail to allow replication of the study. Four studies ${ }^{16-17}$ also lacked detail in the descriptions of their intervention and measurement protocols. In three of the studies skills were inappropriately compared. Richman and Kozlowski ${ }^{15}$ compared communication skills with an unrelated motor skill, which may have had a different rate of development from the communication skills. Pinder and Olswang ${ }^{17}$ and Sigafoos and Couzens ${ }^{18}$ selected skills for treatment and control that were very similar, and which may have been expected to general- ize from the treatment provided.

In each of the studies included in the review, outcomes were measured by the therapists who provided the treatment. Detection bias was reduced, but not eradicated, by a second observer independently measuring outcomes for a percentage of the data. The number of data checked ranged from $17 \%$ to $50 \%$ across the studies. In all studies except that reported by Pinder and Olswang, ${ }^{17}$ data were collected online, with second observers simultaneously collecting data in the reliability sessions. The independence of the assessors was made clear only in Campbell and Stremel-Campbell's ${ }^{21}$ study, which placed the observers 20 feet (approximately $6.1 \mathrm{~m}$ ) apart. Pinder and Olswang ${ }^{17}$ video-recorded sessions and measured outcomes from the videotapes. Measurement reliability was checked by a blinded assessor coding a randomly selected sample of the data.

In single-case experimental designs, treated and control behaviours should be similar in nature and expected to develop at a similar rate. They should be measured continuously across the baseline, treatment, and maintenance phases of the intervention, and these phases should be of similar duration. ${ }^{22,23}$ To demonstrate that treatment is successful, treated and control behaviours should be stable or decrease during baseline. Treated behaviours should increase during treatment, while control behaviours remain stable. In studies aiming for communication development, treated skills should remain high during the maintenance phase. If behaviours are unstable before treatment, randomization tests can be used. ${ }^{24}$ None of the studies included in the review met all criteria to demonstrate clear effects of treatment (see Table I).

Table I: continued

\begin{tabular}{r} 
Outcome measure \\
\hline Requests for more and requests for object \\
were probed once per week in play with toy \\
(experimental condition) and at snack tim \\
(control condition). Unblinded assesso \\
recorded response to elicitations and mode \\
used to make response. Reliability checked \\
with a second observer using randomly \\
selected 20-25\% of data for each child. \\
Agreement $K=0.60$
\end{tabular}

Percentage of time eye contact and head control were maintained during each training session. Vocal imitation was requested 30 times in each session, percentage response recorded. Data collected during each session

by the therapist. Reliability checked with a number of trained observers on $12.5 \%$ session. Mean agreement $92 \%$ (range $80-95 \%$ )

Therapist assessed percentage of trials in which object requested. Reliability of coding established with independent observer using approximately $50 \%$ of sessions. Agreement for baseline session $75 \%$, intervention $95 \%$, generalization $83 \%$
Variation across baseline. Production of targets increased during intervention. Reduced during reversal. Increased again in second treatment phase, but to lower levels than first treatment phase

Variation in baseline. Immediate increase in treatment phase. Possible downward trend at end of treatment
Child absent for 3 sessions over treatment period

Requests for objects generalized across the three objects. All used in same activity, probably interrelated in communication 


\section{Discussion}

The studies included in this review show that SLT based on operant and micro-teaching methods was effective in aiding the development of pre-intentional communication skills, ${ }^{15}$ requests for objects or actions, ${ }^{16,17}$ responses to others' communication, ${ }^{19}$ and the use of expressive language structures ${ }^{21}$ for the children with CP who took part. These studies also show that the children with severe cognitive impairment who participated in research found iconic symbols easier to acquire than non-iconic Blissymbols. ${ }^{20}$ However, given the single-case methodology used in each of the included studies, we cannot generalize the findings to other children with $C P$. Further research is needed to replicate the studies included in this review and to test the general effectiveness of the interventions described with groups of similar children. Furthermore, SLTs are involved in many areas of speech, language, and communication development that are not represented in the current review. Some areas, mostly concerning the introduction and development of augmentative and alternative communication (AAC), were the subject of observational studies ${ }^{23-27}$ which were excluded from the present review because of the inability to demonstrate effectiveness of treatment. However, for some areas of intervention, no evidence was found at all (e.g. dysarthria therapy to aid intelligibility, articulation therapy). This review therefore highlights the current lack of rigorous research evidence of the effectiveness of direct SLT for children with CP.

Research is underway to map out the areas of development in which SLTs are involved and the models and types of intervention currently used (Pennington, Forthcoming). To demonstrate conclusively the effectiveness of these interventions, SLT researchers must ensure that future research is of high quality. In common with research involving other communicatively impaired populations, many studies of SLT for children with CP have failed to describe the participants in sufficient detail to allow replication or implementation, and contain methodological inadequacies that prevent firm conclusions being drawn about the effects of treatment. ${ }^{28-30}$ Future research must provide full descriptions of participants, giving information on their chronological age; type and severity of CP; presence and severity of intellectual and sensory impairment; current levels of motor, cognitive, and sensory function; presence and severity of challenging behaviour; presence, type, and severity of epilepsy; and other health markers. Children's speech production should be described, with a rating of intelligibility. Their receptive and expressive spoken, written, and augmentative and alternative language skills, including measures of vocabulary development, should also be described. Information on the child's preferred methods or modes of communication and the ways they are used in conversation should always be given, with an overall rating of their communicative competence.

With the provision of full descriptions of children with $\mathrm{CP}$ who participate in SLT research it may be possible to identify subgroups of children who have similar features and who may respond similarly to some types of intervention. If such subgroups are found, pragmatic tests of the general effectiveness of interventions to which subgroups respond similarly, could be undertaken. It is possible that some treatments may also be extended to children who do not have CP but who share features with children in a CP subgroup, for example, children with acquired motor impairments, and children with severe learning difficulties who do not have motor impairments. However, given the heterogeneous nature of $\mathrm{CP}$, some children may never fit into a subgroup and for them treatment effectiveness must always be investigated using singlecase experimental designs. ${ }^{11,31}$ Full descriptions of participants would also enable readers to estimate the effects of confounding variables on the outcome of interventions.

In addition to developing research reporting, researchers must also address research design and conduct in future studies. In single-case experiments, behaviours should be assigned at random to treatment and control conditions and be measured continuously throughout each phase of the experiment. ${ }^{11,22,23}$ Each phase should be of adequate duration to show behaviour patterns. In all research, authors should also show that detection bias was reduced by outcomes being measured by observers who did not give the treatment and who were blind to the assignment of participant or target behaviour to treatment or control. ${ }^{32}$

All of the research located in the review approached intervention from a clinician's perspective. Future research should also address the priorities of children and their families, and investigate their views on the acceptability and usefulness of individual treatments. Consumer involvement in research planning and management can go some way towards these goals, and is now being addressed in research into the use of augmentative and alternative communication systems, ${ }^{33,34}$ but has not yet become routine practice in SLT research. ${ }^{35}$ By combining the views of families and clinicians future research will generate acceptable and effective treatments.

\section{Conclusions}

Studies included in this review show that direct SLT, which focuses on communication and expressive language and which uses operant and micro-teaching techniques, has been effective for the children with $\mathrm{CP}$ who participated. Further research is needed to replicate these interventions with other children, and to develop a framework of tested, acceptable interventions that address the full range of speech, language, and communication disorders associated with CP.

DOI: $10.1017 / S 0012162205000101$

Accepted for publication 6th August 2004.

\section{Acknowledgements}

This work was partly funded by a BT bursary awarded to the first author, who is supported by The Health Foundation and the Department of Health NHS R\&D Programme. We thank Carol Davis and Pam Hunt for providing additional information about the included studies, and all the researchers who provided information about conference reports.

A version of this review is published in The Cochrane Library (Pennington et al. 2004). Cochrane reviews are regularly updated as new evidence emerges and in response to comments and criticisms, and The Cochrane Library should be consulted for the most recent version of the review. The results of a Cochrane Review can be interpreted differently, depending on people's perspectives and circumstances. Please consider the conclusions presented carefully. They are the opinions of review authors, and are not necessarily shared by the Cochrane Collaboration. If you wish to comment on this, or other Cochrane reviews of interventions for impairments associated with CP, please write to: Movement Disorders Cochrane Review Group, Instituto de Farmacologia e Terapêutica Geral, Faculdade de Medicina de Lisboa, Hospital de Santa Maria, 1649 028 Lisboa, Portugal; e-mail: movementdisord@fm.ul.pt. 
References

1. Aicardi J, Bax M. (1992) Cerebral palsy. In: Aicardi J, editor. Diseases of the Nervous System in Childhood. London: Mac Keith Press. p 330-367.

2. Watson L, Stanley F, Blair E. (1999) Report of the Western Australian Cerebral Palsy Register - to the Birth Year 1994. Perth: Western Australian Cerebral Palsy Register.

3. Hayden DA, Square PA. (1994) Motor speech treatment hierarchy: a systems approach. Clin Commun Disord 4: 162-174.

4. Strand EA. (1995) Treatment of motor speech disorders in children. Semin Speech Lang 16: 126-139.

5. Ratcliff A, Little M. (1996) A conversation based barrier task approach to teach sight-word vocabulary to a young augmentative communication system user. Child Lang Teach Ther 12: 128-135.

6. Buzolich MJ, KingJS, Baroody SM. (1991) Acquisition of the commenting function among system users. AAC: Augment Altern Commun \%: 88-99.

7. Letto M, Bedrosian JL, Skarakis-Doyle E. (1994) Application of Vygotskian developmental theory to language acquisition in a young child with cerebral palsy. AAC: Augment Altern Commun 10: $151-160$.

8. Carter M, Maxwell K. (1998) Promoting interaction with children using augmentative communication through a peer-directed intervention. Int J Disabil Dev Educ 45: 75-96.

9. Pennington L, Goldbart J, Marshall J. (2004) Speech and language therapy to improve the communication of children with cerebral palsy (Cochrane Review). In: The Cochrane Library. Issue 2. Chichester, UK: John Wiley.

10. Centre for Reviews and Dissemination. (2001) Undertaking Systematic Review of Research on Effectiveness: CRD's Guidance for those Carrying out or Commissioning Reviews. 2nd edn. York: Centre for Reviews and Dissemination.

11. Schlosser RW. (2003) Single subject experimental designs. In: Schlosser RW, editor. The Efficacy of Augmentative and Alternative Communication: Toward Evidence-based Practice. New York: Academic Press. p 86-146.

12. Barlow DH, Hersen M. (1985) Single Case Experimental Designs. New York: Pergamon Press.

13. Kazdin AE. (1982) Single-case Research Designs: Methods for Clinical and Applied Settings. Oxford: Oxford University Press.

14. Cochrane Collaboration. (2002) Review Manager (RevMan) 4.2. Oxford: Cochrane Collaboration.

15. Richman JS, Kozlowski NL. (1977) Operant training of head control and beginning language for a severely developmentally disabled child.J Behav Ther Exp Psychiatry 8: 437-440.

16. Hunt P, Goetz L, Alwell M, Sailor W. (1986) Using an interrupted behavior chain strategy to teach generalized communication responses. J Assoc Persons Severe Handicap 11: 196-204.

17. Pinder GL, Olswang LB. (1995) Development of communicative intent in young children with cerebral palsy: a treatment efficacy study. Infant-Toddler Interv 5: 51-70.

18. Sigafoos J, Couzens D. (1995) Teaching functional use of an eye gaze communication board to a child with multiple disabilities. BrJDev Disabil 81: 114-125.

19. Davis CA, Reichle J, Southard K, Johnston S. (1998) Teaching children with severe disabilities to utilize nonobligatory conversational opportunities: an application of high-probability requests. J Assoc Persons Severe Handicap 23: 57-68.
20. Hurlbut BI, Iwata BA, Green JD. (1982) Nonvocal language acquisition in adolescents with severe physical disabilities: Blissymbol versus iconic stimulus formats. JAppl Behav Anal 15: $241-258$.

21. Campbell CR, Stremel-Campbell K. (1982) Programming "loose training" as a strategy to facilitate language generalization.J Appl Behav Anal 15: 295-301.

22. Edgington ES. (1995) Randomization Tests. 3rd edn. New York: Marcel Dekker.

23. Udwin O, Yule W. (1990) Augmentative communication systems taught to cerebral palsied children - a longitudinal study. I. The acquisition of signs and symbols, and syntactic aspects of their use over time. BrJ Disord Commun 25: 295-309.

24. Udwin O, Yule W. (1991) Augmentative communication systems taught to cerebral-palsied children - a longitudinal study: II. Pragmatic features of sign and symbol use. BrJDisord Commun 26: 137-148.

25. Bruno J. (1990) Customizing a Minspeak system for a preliterate child: a case example. AAC: Augment Altern Commun 5: 89-100.

26. Cohen KJ, Light JC. (2000) Use of electronic communication to develop mentor-protege relationships between adolescent and adult AAC users: pilot study. AAC: Augment Altern Commun 16: 230-238.

27. Koppenhaver DA, Erickson KA, Harris B, McLellan J, Skotko BG, Newton RA. (2001) Storybook-based communication intervention for girls with Rett syndrome and their mothers. Disabil Rebabil 23: 149-159.

28. Enderby P, Emerson J. (1995) Does Speech and Language Therapy Work? A Review of the Literature Commissioned by the Department of Health. London: Whurr.

29. Bedrosian JL. (2003) On the subject of subject selection in AAC. In: Schlosser RW, editor. The Efficacy of Augmentative and Alternative Communication: Toward Evidence-Based Practice. New York: Academic Press. p 58-85.

30. Law J, Garret Z, Nye C. (2004) Speech and language therapy interventions for children with primary speech and language disorder. In: The Cochrane Library. Issue 2. Chichester: John Wiley.

31. Granlund M, Olsson C. (1999) Efficacy of communication intervention for presymbolic communicators. AAC: Augment Altern Commun 15: 25-37.

32. Pocock SJ. (1983) Clinical Trials. A Practical Approach. Chichester: John Wiley.

33. Clarke M, McConachie H, Price K, Wood P. (2001) Views of young people using augmentative and alternative communication systems. Int J Lang Commun Disord 36: 107-115.

34. Balandin S, Raghavendra P. (1999) Challenging oppression: augmented communicators involvement in AAC research. In: Loncke FT, Clibbens J, Arvidson HH, Lloyd LL, editors. Augmentative and Alternative Communication: New Directions in Research and Practice. London: Whurr. p 262-277.

35. Glogowska M, Campbell R. (2000) Investigating parental views on involvement in pre-school speech and language therapy. Int J Lang Commun Disord 35: 391-406.

NB: A list of excluded studies is available from the first author. 